\title{
Malaria epidemiology in an area of stable transmission in tribal population of Jharkhand, India
}

\author{
Manoj K. Das ${ }^{1}$, Brijesh K. Prajapati ${ }^{2}$, Régis W. Tiendrebeogo ${ }^{3,4,5}$, Kumud Ranjan ${ }^{2}$, Bright Adu ${ }^{6}$, Amit Srivastava $^{7}$, \\ Harvinder K. Khera ${ }^{7}$, Narendra Chauhan7, Sanjay Tevatiya ${ }^{2}$, Ikhlaq H. Kana ${ }^{3,4,5}$, Surya Kant Sharma ${ }^{2 *}$, \\ Subhash Singh ${ }^{7^{*}}$ and Michael Theisen ${ }^{3,4,5^{*}}$
}

\begin{abstract}
Background: Malaria remains an important health problem in India with approximately 1 million cases in 2014. Of these, $7 \%$ occurred in the Jharkhand state mainly in the tribal population.

Methods: This study was conducted in Dumargarhi, a tribal village about $42 \mathrm{~km}$ east of Ranchi city, Jharkhand, from May 2014 to September 2016. Four point prevalence surveys were carried out during consecutive high (OctoberDecember) and low (June-August) transmission seasons. Malaria cases were recorded from April 2015 to April 2016 through fortnightly visits to the village. Adult mosquito densities were monitored fortnightly by manual catching using suction tube method.

Results: The study area consists of five hamlets inhabited by 945 individuals living in 164 households as recorded through a house-to-house census survey performed at enrollment. The study population consisted predominantly of the Munda $(n=425,45 \%)$ and Oraon $(n=217,23 \%)$ ethnic groups. Study participants were categorized as per their age $0-5,6-10,11-15$ and $>15$ years. There were 99 cases of clinical malaria from April 2015 to April 2016 and all malaria cases confirmed by microscopy were attributed to Plasmodium falciparum (94 cases) and Plasmodium vivax ( 5 cases), respectively. During the high transmission season the mean density of $P$. falciparum parasitaemia per age group increased to a peak level of 23,601 parasites/ $\mu$ in the 6-10 years age group and gradually declined in the adult population. Malaria attack rates, parasite prevalence and density levels in the study population showed a gradual decrease with increasing age. This finding is consistent with the phenomenon of naturally acquired immunity against malaria. Three vector species were detected: Anopheles fluviatilis, Anopheles annularis, and Anopheles culicifacies. The incoherence or complete out of phase pattern of the vector density peaks together with a high prevalence of parasite positive individuals in the study population explains the year-round malaria transmission in the study region.

Conclusions: The collection of clinical data from a well-characterized tribal cohort from Jharkhand, India, has provided evidence for naturally acquired immunity against malaria in this hyperendemic region. The study also suggests that enforcement of existing control programmes can reduce the malaria burden further.
\end{abstract}

Keywords: Malaria, Plasmodium falciparum, Plasmodium vivax, Morbidity, Age, Jharkhand, India

\footnotetext{
*Correspondence: suryaksharma@gmail.com; subhash@iiim.res.in; mth@

ssi.dk

${ }^{2}$ National Institute of Malaria Research, Indian Council of Medical

Research, New Delhi 110077, India

${ }^{3}$ Department for Congenital Disorders, Statens Serum Institut, Artillerivej

5, 2300 Copenhagen, Denmark

${ }^{7}$ Indian Institute of Integrative Medicine, Canal Road, Jammu 180001,

India

Full list of author information is available at the end of the article
} 


\section{Background}

Malaria is a vector borne disease caused by five different Plasmodium species. Of these, Plasmodium falciparum and Plasmodium vivax are the main causes of disease and mortality worldwide [1]. Today, malaria is primarily confined to the poorest tropical areas of Africa, Asia and Latin America, where it contributes as one of the world's greatest public health problems.

In India, about 1.0 million malaria cases were reported in 2014 of which approximately 7\% originate from Jharkhand state (National Vector Borne Disease Control Programme of the Government of India). The forest, hilly terrain, favorable climate, inaccessible area, tribal culture, migration and social unrest are the main contributing factors to the malaria burden in Jharkhand [2]. An estimated 54 million tribals belonging to about 40 ethnic communities (constituting around $28 \%$ of the total population of Jharkhand) reside in the forest areas. This tribal population accounts for $8 \%$ of the total population of India but contributes to $30 \%$ of all malaria cases [3]. Introduction of new epidemiological tools, bivalent rapid diagnostic test (RDT) kits for diagnosis, artemisininbased combination therapy (ACT) for the treatment of $P$. falciparum malaria and long lasting insecticidal nets (LLINs) has reduced the annual parasite incidence (API) of Jharkhand state from 6.20 in 2010 to 2.55 in 2015 (MK Das and SK Sharma, unpublished). Despite these improvements, malaria remains a major public health problem causing morbidity and mortality in this region.

Individuals who are naturally exposed to malaria develop a strong strain-transcending immunity $[4,5]$ which takes years of exposure to develop and is characterized by a low grade parasitaemia in the presence of vigorous $P$. falciparum-specific immune responses [6]. This immunity, termed premunition, has been extensively characterized in Africa [7-10] primarily because this is where the heaviest malaria related morbidity and mortality occurs [1]. However, with the current focus on malaria eradication, it has become more crucial than ever to investigate malaria epidemiology in other parts of the world. Few such studies have been performed on the Indian sub-continent where malaria transmission rates vary considerably over short geographical distances [11, 12].

The present study describes the demographic profile and provides an overview of the malaria transmission dynamics in a malaria endemic tribal population in Jharkhand, India.

\section{Methods}

\section{Study design, area, and population}

This study was conducted in Dumargarhi village (Ranchi district; Fig. 1; Table 1) about $42 \mathrm{~km}$ east of Ranchi city,
Jharkhand from May 2014 to September 2016. The study included four cross sectional surveys (CSS) to determine the point prevalence of $P$. falciparum and $P$. vivax during high and low transmission periods, respectively (Fig. 1d). A longitudinal cohort survey (LCS) was conducted between April 2015 and April 2016 to determine the burden of clinical malaria (Fig. 1d). The study area is situated in a forested area with terrain full of high and lowlands and a tropical humid climate. It receives high rainfall during Southwest monsoon (mid-May-September) and low rainfall during Northeast monsoon (December-February) with an average annual rainfall of $153 \mathrm{~cm}$. The weather seasons are hot dry summer from April to midMay, a monsoon from mid-May to September, autumn from October to November, winter from December to January, and spring from February to March. The maximum temperature during summer rises to around $41{ }^{\circ} \mathrm{C}$ and the minimum temperature during winter falls to about $5{ }^{\circ} \mathrm{C}$. The relative humidity ranges between 35 and $90 \%$. Malaria transmission occurs year round but peaks after the monsoon season from October to December. The study village consists of five hamlets located $1-3 \mathrm{~km}$ from each other; these hamlets are connected by an allweather road. The nearest primary health center (PHC) is located $20 \mathrm{~km}$ from the study site. The study population belonged to different ethnic groups consisting of the Munda and the Oraon (the major ethnic groups) and the other remaining ethnic groups were the Lohra, Bedia, Baraik and Kachhap. Each ethnic community has its own socio-cultural traditions but they live in harmony with other groups. Inter marriages between different ethnic communities are rare and not solicited by the community leaders. Most villagers work as subsistence farmers, but some are engaged as daily wage laborers. Village children attend a local primary school where they get free mid-day meal under the Central Government sponsored scheme to prevent malnutrition among school going children and also as an incentive to prevent school drop outs.

\section{Longitudinal cohort surveys (LCS)}

Malaria cases were recorded from April 2015 to April 2016 in a longitudinal cohort study. An episode of clinical malaria was defined as fever (auxiliary temperature $\geq 36.5{ }^{\circ} \mathrm{C}$, measured or reported) with slide positive for any asexual $P$. falciparum and/or P. vivax parasitaemia and/or at least one other sign of malaria such as vomiting, diarrhoea, or malaise. A trained field worker visited every house in all hamlets once in a fortnight on a fixed schedule for active surveillance which involved recording auxiliary temperature and all febrile individuals were examined using a rapid diagnostic test (RDT) kit [SD Bioline Malaria Ag Pf/HRP-2/pLDH, 3 band kit Alere Inc.]. RDT positive cases were examined by thick 
a

b

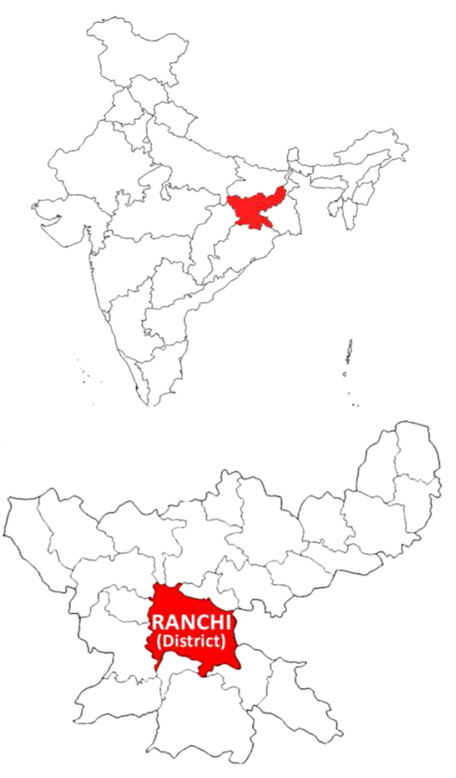

c

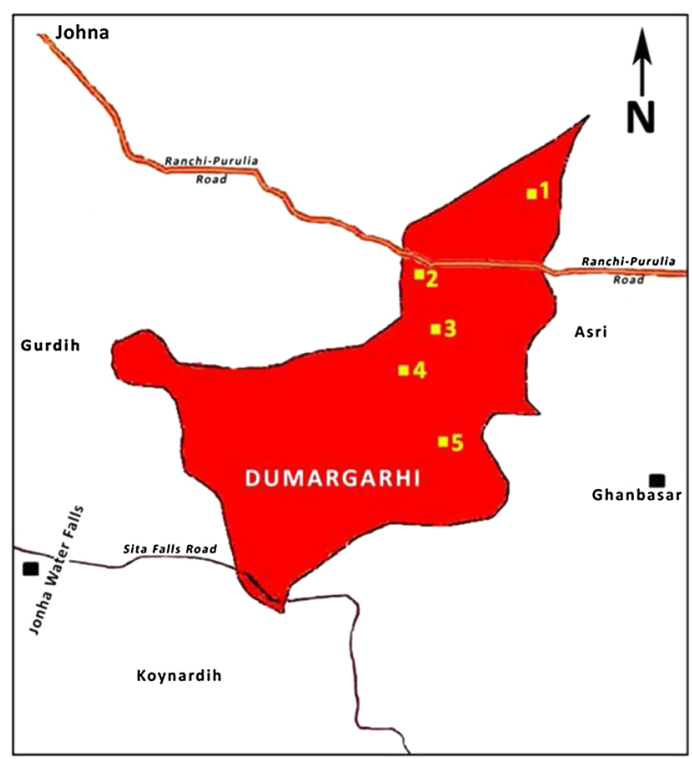

d

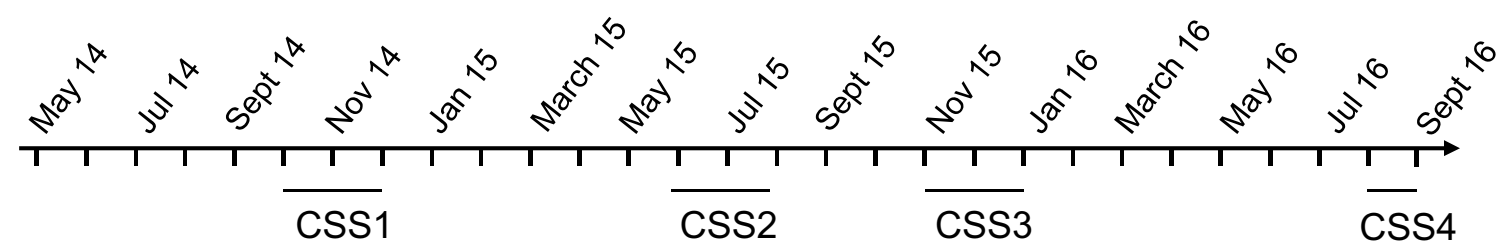

LCS

Fig. 1 Map of the study region showing locations of a Jharkhand state in the Union of India. b Ranchi District. c Study site in Ranchi district including the hamlets Karam Tungri (1), Jarawadih (2), New Torang (3), Old Torang (4), and Dumargarhi (5). d Timing and duration of cross sectional (CSS) and longitudinal surveys (LCS) is shown

and thin blood smears from finger prick blood samples. All slides collected from the study area were brought to a laboratory at the National Institute of Malaria Research field unit, Itki, Ranchi. Slides were examined by trained microscopists under compound microscope at $100 \times$ magnification after staining with Jaswant Singh Bhattacharjee (JSB) stain (Rankem, India). Asexual parasites were counted against 200 leukocytes and parasite density was calculated as number of asexual parasites per micro liter of blood assuming a mean normal leukocyte count of $8000 / \mu \mathrm{L}$. Slide-positive cases were provided antimalarial treatment as per the guidelines of the National Vector Borne Disease Control Programme of the Government of India [13, 14]. A blood smear was classified negative if no parasite was found in 100 random microscopic fields. In between the fortnightly visits, passive surveillance of malaria cases was maintained through telephonic reporting of any febrile cases to the trained field worker by family members of the patient. Confirmation of these reported cases was done by the trained field worker through use of RDT kit and malaria positive cases were treated as described above. Presumptive treatment was not given to the patients.

\section{Cross-sectional surveys (CSS)}

Four point prevalence surveys were carried out in all hamlets twice during peak transmission (OctoberDecember) and twice during low malaria transmission seasons (June-August). All villagers who were available and willing to participate were included in these surveys. The study subjects were examined for malaria by RDT kit and microscopy of blood smears was performed irrespective of clinical symptoms. Malaria cases were treated as per the national drug policy described above. 
Table 1 Demographic and baseline characteristics

\begin{tabular}{|c|c|c|c|c|c|c|c|}
\hline Factor & Dumargarhi & Jarwadih & New Torang & Karam Tungri & Old Torang & Total & $P$ value* \\
\hline Number of individuals (\%) & $186(19.7)$ & $103(10.9)$ & $84(8.9)$ & $123(13.0)$ & $449(47.5)$ & $945(100.0)$ & \\
\hline \multicolumn{8}{|l|}{ Age group (years) } \\
\hline $0-5$ & $14(1.5)$ & $9(0.9)$ & $9(0.9)$ & $9(0.9)$ & $71(7.5)$ & $112(11.9)$ & \\
\hline $6-10$ & $30(3.2)$ & $11(1.2)$ & $5(0.5)$ & $18(1.9)$ & $45(4.8)$ & $109(11.5)$ & \\
\hline $11-15$ & $19(2.0)$ & $9(1.0)$ & $8(0.8)$ & $19(2.0)$ & $33(3.5)$ & $88(9.3)$ & \\
\hline$\geq 16$ & $123(13.0)$ & $74(7.8)$ & $62(6.6)$ & $77(8.1)$ & $300(31.7)$ & $636(67.3)$ & 0.001 \\
\hline \multicolumn{8}{|l|}{ Sex } \\
\hline Female & $90(9.5)$ & $49(5.2)$ & $42(4.4)$ & $56(5.9)$ & $215(22.8)$ & $452(47.8)$ & \\
\hline Male & $96(10.2)$ & $54(5.7)$ & $42(4.4)$ & $67(7.1)$ & $234(24.8)$ & $493(52.2)$ & 0.99 \\
\hline \multicolumn{8}{|l|}{ Education } \\
\hline G & $1(0.1)$ & $0(0.0)$ & $0(0.0)$ & $1(0.1)$ & $0(0.0)$ & $2(0.2)$ & \\
\hline $\mathrm{H}$ & $15(1.8)$ & $7(0.9)$ & $26(3.2)$ & $33(4.1)$ & $43(5.3)$ & $124(15.3)$ & \\
\hline 1 & $82(10.1)$ & $31(3.8)$ & $22(2.7)$ & $30(3.7)$ & $204(25.1)$ & $369(45.4)$ & \\
\hline $\mathrm{Mi}$ & $31(3.8)$ & $4(0.5)$ & $22(2.7)$ & $29(3.6)$ & $48(5.9)$ & $134(16.5)$ & \\
\hline $\operatorname{Pr}$ & $33(4.1)$ & $13(1.6)$ & $6(0.7)$ & $18(2.2)$ & $74(9.1)$ & $144(17.7)$ & \\
\hline$U$ & $12(1.5)$ & $1(0.1)$ & $0(0.0)$ & $0(0.0)$ & $26(3.2)$ & $39(4.8)$ & $<0.005$ \\
\hline \multicolumn{8}{|l|}{ Profession } \\
\hline A & $33(20.5)$ & $16(9.9)$ & $13(8.1)$ & $20(12.4)$ & $77(47.8)$ & $159(98.8)$ & \\
\hline NIL & $0(0.0)$ & $0(0.0)$ & $1(0.6)$ & $0(0.0)$ & $0(0.0)$ & $1(0.6)$ & \\
\hline S & $1(0.6)$ & $0(0.0)$ & $0(0.0)$ & $0(0.0)$ & $0(0.0)$ & $1(0.6)$ & 0.159 \\
\hline \multicolumn{8}{|l|}{ Income } \\
\hline$[0-50,000]$ & $25(15.3)$ & $20(12.3)$ & $13(8.0)$ & $20(12.3)$ & 71 (43.6) & $149(91.4)$ & \\
\hline$[50,000-100,000]$ & $8(4.9)$ & $0(0.0)$ & $0(0.0)$ & $0(0.0)$ & $6(3.7)$ & $14(8.6)$ & 0.002 \\
\hline \multicolumn{8}{|l|}{ Housing } \\
\hline M & $182(20.1)$ & $100(11.0)$ & $34(3.7)$ & $113(12.5)$ & $431(47.5)$ & $860(94.8)$ & $<0.005$ \\
\hline$P$ & $0(0.0)$ & $0(0.0)$ & $8(0.9)$ & $0(0.0)$ & $0(0.0)$ & $8(0.9)$ & \\
\hline $\mathrm{T}$ & $0(0.0)$ & $0(0.0)$ & $39(4.3)$ & $0(0.0)$ & $0(0.0)$ & $39(4.3)$ & \\
\hline \multicolumn{8}{|l|}{ Bednet } \\
\hline $\mathrm{N}$ & $142(15.7)$ & $100(11.0)$ & $81(8.9)$ & $113(12.5)$ & $367(40.5)$ & $803(88.5)$ & \\
\hline Y & $40(4.4)$ & $0(0.0)$ & $0(0.0)$ & $0(0.0)$ & $64(7.1)$ & $104(11.5)$ & $<0.005$ \\
\hline
\end{tabular}

Education: $G$ graduate, $H$ high school education (intermediate), I illiterate, Mi middle, Pr primary, $U$ undergraduate; Profession: $A$ agriculture, $N I L$ no profession, $S$ service; Housing: $M$ mud walls with thatched roof, $P$ cement walls and roof, $T$ brick walls with tin roof, Bednet: $Y$ yes; $N$ no

* $P$ value is based on Chi Square test

Common ailments were treated by the health-care workers, whereas individuals with serious life threatening diseases such as TB, hypertension, respiratory and liver disorders were referred to Angara primary health center or to a referral hospital located in Ranchi city. The relevant information for each study subject such as name, age, sex, resident status, fever, auxiliary temperature, and other clinical symptoms were recorded in a patient data sheet and a computerized data base for such information was developed.

\section{Vector species and entomological surveys}

The district is characterized by a large network of streams and other water bodies which provide innumerable and diverse breeding sites for species-specific malaria vectors [Anopheles culicifacies, Anopheles fluviatilis and Anopheles annularis (Diptera: Culicidae)] throughout the year. An. culicifacies breeds mainly in pools formed in streams and riverbeds; the most productive breeding sites of An. fluviatilis are slow-moving streams while An. annularis breeds in margins of ponds, rivers and streams with abundant vegetation. The three vector species $A n$. culicifacies (sibling species B \& C), An. fluviatilis (sibling species $\mathrm{T}$ ) and An. annularis (sibling species A) were identified based on their morphological characteristics and cytogentic analysis of their polytene chromosomes [15].

Entomological survey was conducted fortnightly from May 2014 to March 2016 by manual catching using suction tube method [16, 17]. Indoor resting collections 
were made in the morning between 06:00 and 08:00 $h$ from four randomly selected human dwellings and four cattle sheds. Mosquitoes from each dwelling were kept separately in test tubes and species were identified based on morphology [18-20]. The sibling species identity of the captured vector species was determined through cytogenetic analysis of the polytene chromosomes [15]. Densities per person-hour searching (person-hour density or PHD) of total anophelines and vector species were determined.

\section{Statistical analysis}

Statistical analysis was done with the R 3.3.0 and GraphPad Prism 5 software. Age was categorized in four levels $(0-5,6-10,11-15$ and $>15$ years $)$ and demographic characteristics were compared between villages by using the $X^{2}$-test. $P$ values $<0.05$ were considered to indicate statistical significance.

\section{Results}

\section{Population characteristics}

The study area consists of five hamlets inhabited by 945 individuals living in 164 households as recorded through a house-to-house census performed at enrollment. The population distribution within these hamlets were Dumargarhi $(\mathrm{n}=186)$, Jarwadih $(\mathrm{n}=103)$, New Torang $(\mathrm{n}=84)$, Karam Tungri $(\mathrm{n}=123)$ and Old Torang $(\mathrm{n}=449)$ (Table 1$)$. The mean age of the study population was $27.5 \pm 18.8$ years. Villagers were divided into 4 age groups: $\leq 5$ years $(\mathrm{n}=112,11.9 \%), 6-10$ years $(\mathrm{n}=109,11.5 \%), 11-15$ years $(\mathrm{n}=88,9.3 \%)$ and $>15$ years $(n=636,67.3 \%)$. The study population consisted predominantly of the Munda $(\mathrm{n}=425,45 \%)$ and Oraon ( $\mathrm{n}=217,23 \%)$ ethnic groups. The remaining villagers belonged to Lohra, Bedia, Baraik and Kachhap ethnic groups. Individuals who used bed net constituted 11.5\% of the population. The gender distribution was not significantly different between villages $(P<0.99)$ while the distribution of age, bed net use, housing, income was significantly different between villages $\left(\mathrm{P}<0.005, \mathrm{X}^{2}\right.$ analysis) (Table 1).

\section{Plasmodium falciparum infections recorded through fortnightly surveillance}

Malaria transmission was perennial and P. falciparum malaria was reported throughout the year (Fig. 2). There were 99 cases of clinical malaria from April 2015 to April 2016 and all cases confirmed by microscopy were attributed to P. falciparum (94 cases) and P. vivax (5 cases), respectively. The monthly incidence of $P$. falciparum and P. vivax is shown in Fig. 2. P. falciparum malaria incidence was generally higher after the end of the monsoon season and lower in the hot dry summer months. The

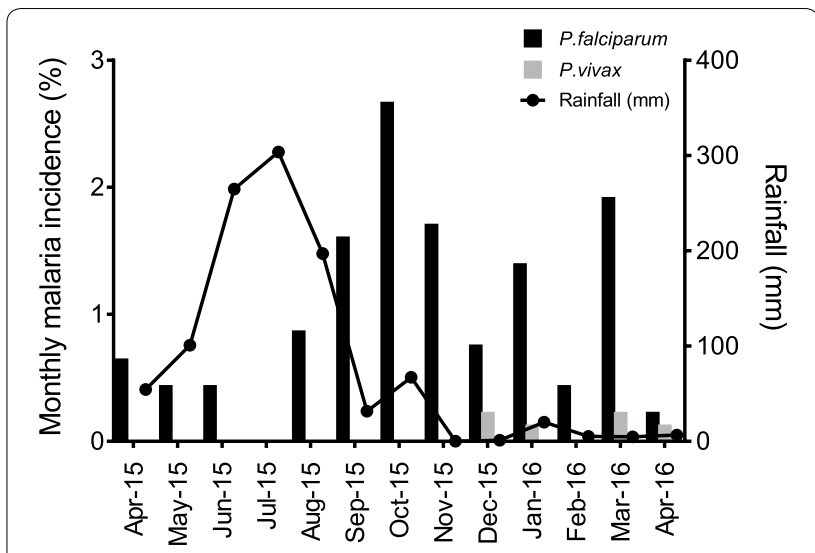

Fig. 2 Monthly malaria incidence (cases per 945 population) in the Ranchi study cohort from April 2015 to April 2016. During this period there were 94 P. falciparum and 5 P. vivax cases diagnosed with febrile malaria. Monthly incidence of $P$. falciparum (black bars), P. vivax (grey bars) is shown. The line plot is the monthly rainfall recorded during the period

mean density of $P$. falciparum parasitaemia was calculated for the $0-5,6-10,11-15$, and $>15$ year age groups, respectively (Fig. 3a). It increased to a peak level of 23,601 parasites/ $\mu \mathrm{l}$ in the $6-10$ years age group and gradually declined in the adult population to a level of 7066 parasites/ $\mu \mathrm{l}$. A similar pattern was observed in the incidence rate of febrile $P$. falciparum malaria (Fig. 3b).

\section{Malaria parasite prevalence during high and low transmission periods}

During the high transmission season (CSS1 and CSS3), 386 and 327 villagers respectively were examined for $P$. falciparum and P. vivax infections by RDT kit (Table 2). Of these, 180 were positive for malaria parasites $(P f=148, P v=10$, mixed infection $=22)$ in CSS1 and 72 were positive for malaria $(P f=59, P v=9$, mixed infection $=4$ ) in CSS3. The parasite rate during the first and second surveys in the high transmission was 46.6 and $22 \%$ respectively. During low transmission (CSS2 and CSS4), 254 and 225 individuals were enrolled, $50 \%$ of whom had also participated in CSS1. Of these, 51 individuals were malaria positive by the RDT test in CSS2 $(P f=46, P v=2$, mixed infections $=3)$ and 39 were positive for malaria in CSS4 $(P f=35, P v=4)$. The parasite rate during the two surveys in the low transmission was 20.1 and $17.3 \%$ respectively. The average parasite rate during the high (CSS1 + CSS3) and low (CSS2 + CSS4) transmission season was 35.3 and $18.8 \%$, respectively. A significant variation in the seasonal malaria prevalence $\left(\mathrm{P}<0.0007, \mathrm{X}^{2}\right.$ analysis) was observed.

Eighty-six (47.8\%) and 13 (25.5\%) of the RDT positive samples were also found to be slide positive for $P$. 

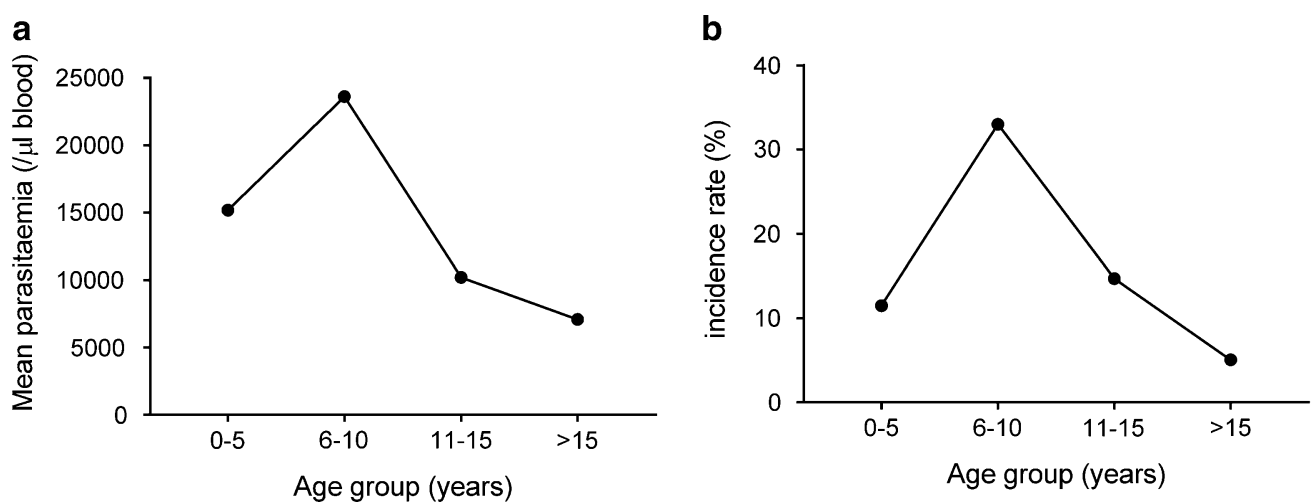

Fig. 3 Mean P. falciparum density and febrile malaria incidence per age-group. a Mean parasite density of all slide positive P. falciparum malaria cases recorded during the longitudinal follow-up from April 2015 to April 2016 was calculated per age groups. b Incidence rate of febrile malaria in the same age groups

falciparum from CSS1 and CSS2, respectively. The mean P. falciparum parasite density of these slide positive individuals was $6113( \pm 1456)$ parasites/ $\mu \mathrm{l}$ and $3480( \pm 1511)$ parasites/ $\mu \mathrm{l}$ during high and low transmission season, respectively (Table 2 ). The prevalence of $P$. falciparum parasitaemia was highest in children up to 15 years of age and declined in the adult population during both high and low-transmission season (Fig. 4a). During CSS1, there were 44 cases of P. falciparum malaria. The remaining slide positive individuals $(\mathrm{n}=42)$ who did not have fever or any other symptom of malaria were classified as asymptomatic $P$. falciparum carriers. The number of malaria cases and asymptomatic carriers were 4,15 , 10 , and 15 and $3,7,5$, and 27 in the $0-5,6-10,11-15$, and $>15$ years age groups, respectively. The mean parasite density of each age group was plotted for malaria cases and asymptomatic carriers, respectively (Fig. 4b). Parasite densities of acute malaria cases were 66-fold higher in the $0-5$ age group than those of asymptomatic carriers (Fig. 4b). During CSS3 and CSS4 lower prevalence of malaria observed in this study population could be attributed to the ongoing case surveillance during the preceding study period and effective treatment of the malaria positive cases, thereby reducing the parasite transmission.

\section{Malaria vectors and seasonal prevalence}

Average annual vector density determination in the study area established An. fluviatilis as the most prevalent vector constituting $49 \%$ of all the vector species. An. annularis and An. culicifacies constituted 34 and $17 \%$, respectively. The cumulative annual average of all the vectors captured in the study area during fortnightly surveys was 21 and $79 \%$ for vectors resting in human dwellings and cattle sheds, respectively. Some seasonal fluctuations in the month-wise person-hour density (PHD) of An. culicifacies, An. fluviatilis and An. annularis was observed (Fig. 5). The highest density of $A n$. fluviatilis was observed between October and February, whereas the highest density of An. culicifacies and An. annularis was observed between May and September and the lowest during October-April.

\section{Discussion}

Malaria is a focal disease in India, influenced by several local ecological and social factors [21]. The study team collected samples and clinical data from 945 individuals of tribal origin living in closely placed hamlets in the forested hills of Jharkhand in the Eastern parts of India. This study involved four cross-sectional surveys two each during the high (October-December) and the low (June-August) transmission seasons and fortnightly surveillance during the periods intervening the cross-sectional surveys. In summary: (1) malaria transmission was hyper-endemic, and (2) there was evidence suggesting that the population develops naturally acquired immunity (NAI) as a function of age and exposure. The observations that children had (i) a high incidence and prevalence rate of $P$. falciparum infections, (ii) a high malarial attack rate, and (iii) higher parasite densities compared to adults are indications of hyperendemicity in this study area. It is generally observed that individuals living in hyper-endemic areas gradually develop an anti-parasite immunity which protects them from febrile malaria. The age-dependent variation of malaria attack rates, parasite prevalence and density levels in the present study was characterized by a gradual decrease with increasing age. This relationship is typical of NAI against malaria and is similar to findings in highly endemic areas of Africa [22-24] and Asia [25]. 


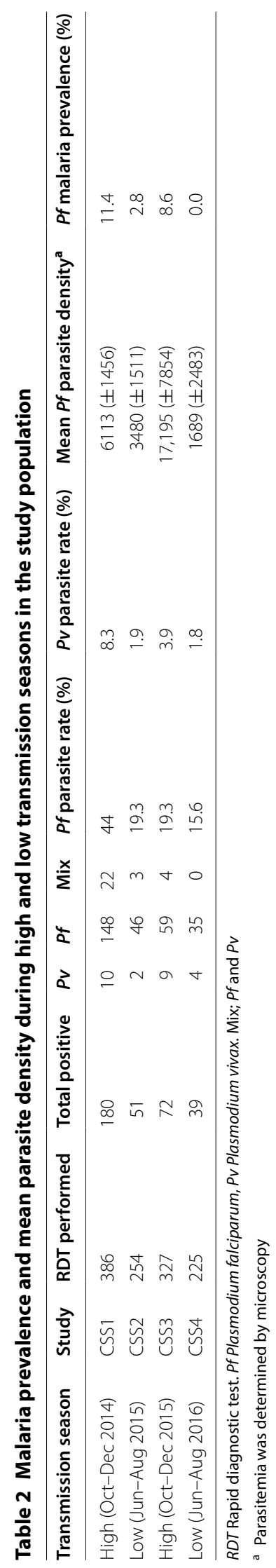



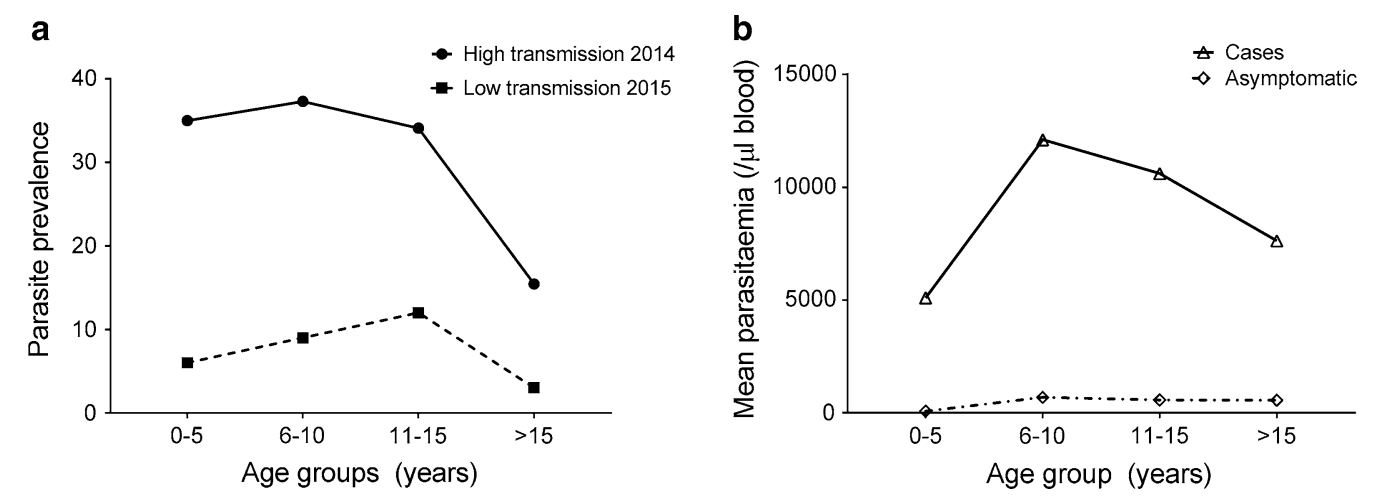

Fig. 4 a Age-dependent prevalence of P. falciparum positive individuals during the high (circles) and the low (squares) transmission seasons. $\mathbf{b}$ Mean P. falciparum density per age group in acute malaria cases (triangles) and asymptomatic carriers (diamonds) during high transmission season in 2014 (CSS1). Parasite densities of acute malaria cases were approximately 66-fold higher than those of asymptomatic carriers in the 0-5 years age group and this threshold decreased with age

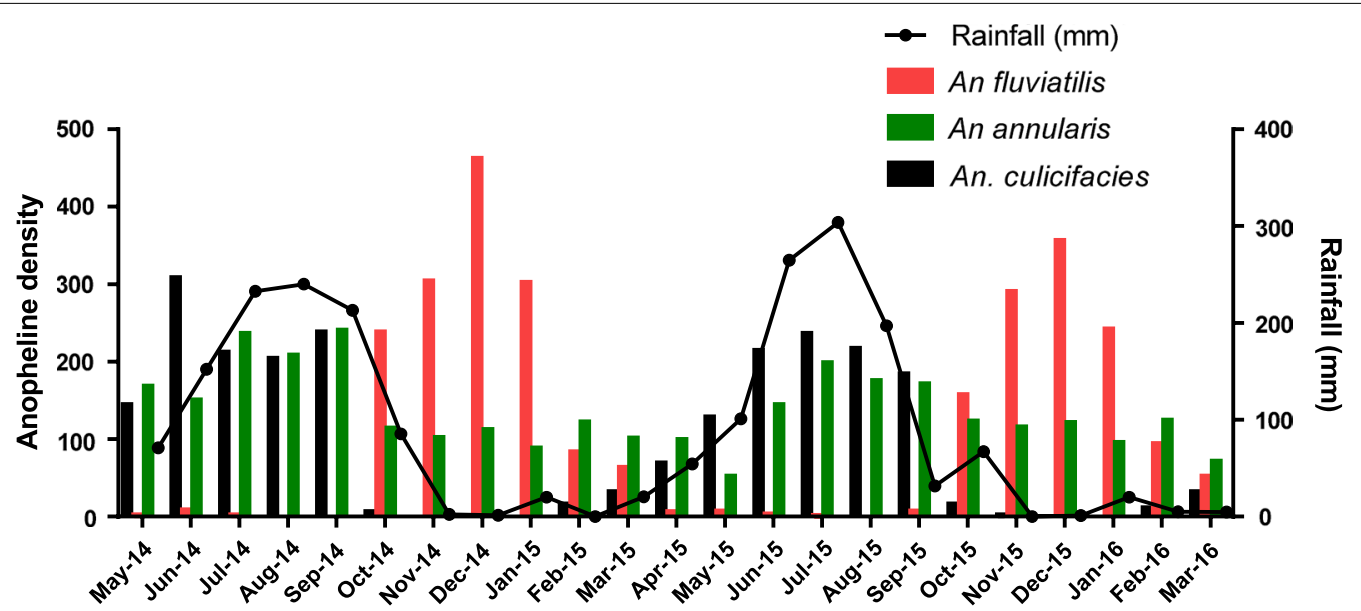

Fig. 5 Monthly density of An. culicifacies (black bars) An. Annularis (green bars), and An. fluviatilis (red bars) in the study area based on indoor resting hand catch collections once every month. The line plot is the monthly rainfall recorded during the period

The development of NAI is further underscored by the very high difference in parasite densities between acute malaria cases and asymptomatic carriers. The authors observed that parasite densities in acute malaria cases were much higher than those in asymptomatic carriers. This difference was particularly high in young children and decreased with age i.e. the parasite density causing fever decreases with age and exposure. This finding is related to the phenomenon of the pyrogenic threshold which has been described in Africa [26]. Similar agedependent decrease in the prevalence of parasitaemia and febrile malaria has also been observed in Odisha, which is located in a neighboring state of India [27]. Another study in the Sundargarh district in Odisha, also demonstrated high levels of agglutinating antibodies against $P$. falciparum infected erythrocytes in healthy adults but not in children below 3 years of age [28]. Collectively these findings support the notion that individuals who live in highly malaria endemic areas of India develop NAI.

Another important observation of the present study was the apparent decrease in the malaria parasite burden between 2014 and 2016. In the first cross-sectional survey during high transmission season of 2014 the rate of $P$. falciparum-positive samples was around $44 \%$ with a clinical malaria prevalence of $11.4 \%$. This was reduced to $19.3 \%$ for $P$. falciparum-positive samples and clinical malaria prevalence of $8.6 \%$ during the next high transmission season. This reduction in the parasite burden in the study population is likely due to the combination of active case detection and ACT of all identified positive cases. 
The entomological studies revealed that the study area is under the influence of three vector species $A n$. fluviatilis and An. culicifacies as the primary vectors and An. annularis as the secondary vector for malaria transmission. The climatic conditions in the forest ecotype are more conducive for higher survival of vectors that are associated with a predominance of $P$. falciparum [3]. An. fluviatilis is widely distributed in India although its role in malaria transmission varies from place to place depending on the local prevalence of different sibling species [29]. An. fluviatilis (species S) is among the most efficient vectors of malaria particularly in hills and foothills of India and it has previously been incriminated as a vector in the tribal districts of Koraput, Orissa [28] and Bastar, Madhya Pradesh [30]. In contrast, other studies have found that An. fluviatilis (species $\mathrm{T}$ ), though prevalent in high densities in the foothills of Shiwalik range was not playing role in malaria transmission [31]. However, An. fluviatilis (species $\mathrm{T}$ ) has been found to be susceptible to $P$. vivax [32] and $P$. falciparum infections (MK Das, unpublished) and has been incriminated as an efficient vector of malaria for transmission in the mountainous areas of the Hormozgan province, south Iran [33]. The role of An. fluviatilis (species $\mathrm{T}$ ) as the primary vector in malaria transmission in this study has been established by way of its high prevalence period coinciding with the peak transmission period, more preference for human biting, high human blood index and susceptibility to plasmodial infections (MK Das, unpublished). The other primary vector, An. culicifacies (species C), is responsible for $60-70 \%$ of all malaria cases in India despite being predominantly a zoophagic species and being prone to environmental factors with epidemiological implications in different ecotypes [12,34]. An. culicifacies may be regarded as playing a complementary role in maintaining perennial transmission during pre-monsoon and monsoon months where transmission is low. The secondary vector $A n$. annularis though primarily zoophagic, exophilic and exophagic, is associated with low human biting rate and sporozoite rate, and has a marginal role in malaria transmission in this study area. While An. annularis plays a limited role for malaria transmission in the present study area, it is responsible for year-round transmission as observed in inlands of Odisha [32] and forests of Assam [35]. The presence of the three vector species and their sibling species complexes reported here together with a high prevalence of parasite positive individuals in the study population explains the year-round malaria transmission.

Besides technical inadequacies, the problem posed by malaria in tribal areas of India is multifaceted. Operational constraints such as inaccessible remote areas, poor surveillance, inadequate vector control and general lack of motivation and health awareness all facilitate persistent transmission. Therefore, focus should be on strengthening of health infrastructure at the periphery to ensure early case detection and prompt treatment. This should be supported by quality vector control measures, creating health awareness in the community and ensuring economic growth of the tribal areas. These efforts along with the development of an efficacious malaria vaccine will lead to a sustained reduction in malaria morbidity and mortality.

\section{Conclusion}

In conclusion, the collection of clinical data from a wellcharacterized tribal cohort from the state of Jharkhand in Eastern India has provided evidence for the presence of NAI against malaria in this hyperendemic region.

\section{Authors' contributions}

SKS, SS and MT designed the study. MKD, BKP, KR, ST and SKS collected the data. AS, HKK and NC processed the samples. RWT, BA, SKS, IHK and MT analysed the data. SKS, SS and MT wrote the manuscript. All authors read and approved the final manuscript.

\section{Author details \\ ${ }^{1}$ Field Unit, National Institute of Malaria Research, Ranchi, Jharkhand, India. ${ }^{2}$ National Institute of Malaria Research, Indian Council of Medical Research, New Delhi 110077, India. ${ }^{3}$ Department for Congenital Disorders, Statens Serum Institut, Artillerivej 5, 2300 Copenhagen, Denmark. ${ }^{4}$ Centre for Medical Parasitology at Department of International Health, Immunology and Micro- biology, University of Copenhagen, Copenhagen, Denmark. ${ }^{5}$ Department of Infectious Diseases, Copenhagen University Hospital, Rigshospitalet, Copenhagen, Denmark. ${ }^{6}$ Noguchi Memorial Institute for Medical Research, University of Ghana, Legon, Ghana. ${ }^{7}$ Indian Institute of Integrative Medicine, Canal Road, Jammu 180001, India.}

\section{Acknowledgements}

The authors are thankful to the Council of Scientific and Industrial Research (CSIR), Indian Council of Medical Research (ICMR) and the Director, National Institute of Malaria Research (ICMR-NIMR) for permitting us to conduct this study. Technical help provided by the field and laboratory staff, Sh. Vijay Om Gupta, LT and Sh. Ramkesh Pandey, LA for their assistance during the course of study is acknowledged. BKP, KR, AS, NC and ST acknowledge DBT for fellowships. HKK acknowledges ICMR for fellowship.

\section{Competing interests}

The authors declare that they have no competing interests.

\section{Availability of data and materials}

The datasets used and analysed in the current study are available from the corresponding author on reasonable request.

\section{Ethics statements}

The study was approved by the Institutional Ethics Committee of the National Institute of Malaria Research (NIMR), Indian Council of Medical Research, New Delhi.

Villagers were informed about the purpose of the study and an informed consent was obtained from study participants or their guardians before enrollment in the study.

\section{Funding}

This work was supported by the Department of Biotechnology (DBT), Government of India (BT/IN/Denmark/13/SS/2013) and the Danish Council for Strategic research (Grant 13127). 


\section{Publisher's Note}

Springer Nature remains neutral with regard to jurisdictional claims in published maps and institutional affiliations.

Received: 17 February 2017 Accepted: 23 April 2017

Published online: 02 May 2017

\section{References}

1. WHO. World Malaria Report 2015. Geneva: World Health Organization; 2015.

2. Saxena R, Das MK, Nagpal BN, Srivastava A, Gupta SK, Kumar A, et al. Identification of risk factors for malaria control by focused interventions in Ranchi district, Jharkhand, India. J Vector Borne Dis. 2014;51:276-81.

3. Sharma VP. Re-emergence of malaria in India. Indian J Med Res. 1996;103:26-45.

4. Cohen S, McGregor A, Carrington S. Gamma globulin and aquired immunity to human malaria. Nature. 1961:192:733-7.

5. McGregor IA, Carrington SP, Cohen S. Treatment of East African P. falciparum malaria with West African gammaglobulin. Trans R Soc Trop Med Hyg. 1963;57:170-5

6. Druilhe $P$, Perignon JL. A hyphothesis about the chronicity of malaria infection. Parasitol Today. 1997;13:353-7.

7. Osier FH, Polley SD, Mwangi T, Lowe B, Conway DJ, Marsh K. Naturally acquired antibodies to polymorphic and conserved epitopes of Plasmodium falciparum merozoite surface protein 3. Parasite Immunol. 2007:29:387-94

8. Dodoo D, Theisen M, Kurtzhals JA, Akanmori BD, Koram KA, Jepsen S, et al. Naturally acquired antibodies to the glutamate-rich protein are associated with protection against Plasmodium falciparum malaria. J Infect Dis. 2000;181:1202-5.

9. Oeuvray C, Theisen M, Rogier C, Trape JF, Jepsen S, Druilhe P. Cytophilic immunoglobulin responses to Plasmodium falciparum glutamate-rich protein are correlated with protection against clinical malaria in Dielmo, Senegal. Infect Immun. 2000;68:2617-20.

10. Taylor RR, Allen SJ, Greenwood BM, Riley EM. IgG3 antibodies to Plasmodium falciparum merozoite surface protein 2 (MSP2): increasing prevalence with age and association with clinical immunity to malaria. Am J Trop Med Hyg. 1998;58:406-13.

11. Sharma SK, Tyagi PK, Padhan K, Upadhyay AK, Haque MA, Nanda N, et al. Epidemiology of malaria transmission in forest and plain ecotype villages in Sundargarh District, Orissa, India. Trans R Soc Trop Med Hyg. 2006;100:917-25

12. Singh N, Mishra AK, Chand SK, Sharma VP. Population dynamics of Anopheles culicifacies and malaria in the tribal area of central India. J Am Mosq Control Assoc. 1999;15:283-90.

13. NVBDCP. National framework for malaria elimination in India 2016-2030. Delhi: National Vector Borne Disease Control Programme; 2016.

14. NIMR. Guidelines for diagnosis and treatment of malaria in India 2011. Delhi: National Institute of Malaria Research; 2011.

15. WHO. Anopheline species complexes in South and South East Asia. Geneva: World Health Organization; 2007.

16. WHO. Manual of entomological techniques. Geneva: World Health Organization; 1975.

17. WHO. Manual on practical entomology in malaria / prepared by the $\mathrm{WHO}$ Division of Malaria andOther Parasitic Diseases. Geneva: World Health Organization; 1995. http://www.who.int/iris/handle/10665/42481.

18. Cristophers SR. The fauna of British India including Ceylon and Burma Diptera. vol. IV. Family Culicidae. Tribe Anophelini. London: Taylor and Francis; 1933.

19. Barraud PJ. The fauna of British India, including Ceylon and Burma. Diptera. vol V. Family Culicidae. Tribes Megarhinini and Culicini. London: Taylor and Francis; 1934
20. Knight KL, Stone A. A catalog of the mosquitoes of the world (Diptera: Culicidae). 2nd ed. Annapolis: Entomological Society of America; 1977. p. 611.

21. Wangdi K, Gatton ML, Kelly GC, Banwell C, Dev V, Clements AC. Malaria elimination in India and regional implications. Lancet Infect Dis. 2016;16:e214-24

22. Bruce-Chwatt LJ. A longitudinal longitudinal survey of natura malaria infection in a group of West African Adults. I. West Afr Med J. 1963;12:141-73.

23. Trape JF, Rogier C, Konate L, Diagne N, Bouganali H, Canque B, et al. The Dielmo project: a longitudinal study of natural malaria infection and the mechanisms of protective immunity in a community living in a holoendemic area of Senegal. Am J Trop Med Hyg. 1994;51:123-37.

24. Marsh K. Malaria-a neglected disease? Parasitology. 1992;104(Suppl):S53-69.

25. Soe S, Aye KS, Win N, Swe T, Perignon JL, Roussilhon C, et al. Premunition against Plasmodium falciparum: demonstration in a malaria hyperendemic village in Southeast Asia, Myanmar. Trans R Soc Trop Med Hyg. 2000;95:81-4

26. Rogier C, Commenges D, Trape JF. Evidence for an age-dependent pyrogenic threshold of Plasmodium falciparum parasitemia in highly endemic populations. Am J Trop Med Hyg. 1996:54:613-9.

27. Sharma SK, Tyagi PK, Padhan K, Adak T, Subbarao SK. Malarial morbidity in tribal communities living in the forest and plain ecotypes of Orissa, India. Ann Trop Med Parasitol. 2004;98:459-68.

28. Chattopadhyay R, Sharma A, Srivastava VK, Pati SS, Sharma SK, Das BS, et al. Plasmodium falciparum infection elicits both variant-specific and cross-reactive antibodies against variant surface antigens. Infect Immun. 2003:71:597-604

29. Nanda N, Joshi H, Subbarao SK, Yadav RS, Shukla RP, Dua VK, et al. Anopheles fluviatilis complex: host feeding patterns of species S, T, and U. J Am Mosq Control Assoc. 1996;12:147-9.

30. Kulkarni SM. Density patterns of anophelines and their relation to malaria in Bastar district, Madhya Pradesh. Indian J Malariol. 1990;27:187-94.

31. Sharma SK, Dua VK, Sharma VP. Field studies on the mosquito repellent action of neem oil. Southeast Asian J Trop Med Public Health. $1995 ; 26: 180-2$

32. Adak T, Singh OP, Das MK, Wattal S, Nanda N. Comparative susceptibility of three important malaria vectors Anopheles stephensi, Anopheles fluviatilis, and Anopheles sundaicus to Plasmodium vivax. J Parasitol. 2005;91:79-82.

33. Fekri S, Vatandoost H, Daryanavard A, Shahi M, Safari R, Raeisi A, et al. Malaria situation in an endemic area, southeastern iran. J Arthropod Borne Dis. 2014;8:82-90.

34. Kulkarni SM. Feeding behaviour of anopheline mosquitoes in an area endemic for malaria in Bastar district, Madhya Pradesh. Indian J Malariol. 1987;24:163-71.

35. Dev V, Hira CR, Rajkhowa MK. Malaria-attributable morbidity in Assam, north-eastern India. Ann Trop Med Parasitol. 2001;95:789-96.

\section{Submit your next manuscript to BioMed Central and we will help you at every step:}

- We accept pre-submission inquiries

- Our selector tool helps you to find the most relevant journal

- We provide round the clock customer support

- Convenient online submission

- Thorough peer review

- Inclusion in PubMed and all major indexing services

- Maximum visibility for your research

Submit your manuscript at www.biomedcentral com/submit
C BioMed Central 